\title{
Pain catastrophizing predicts poor response to topical analgesics in patients with neuropathic pain
}

\author{
Tsipora Mankovsky BA ${ }^{1}$, Mary E Lynch MD², AJ Clark MD³ , J Sawynok PhD, Michael JL Sullivan PhD ${ }^{1}$
}

T Mankovsky, ME Lynch, AJ Clark, J Sawynok, MJL Sullivan. Pain catastrophizing predicts poor response to topical analgesics in patients with neuropathic pain. Pain Res Manage 2012;17(1): $10-14$.

BACKGROUND: Previous research suggests that high levels of pain catastrophizing might predict poorer response to pharmacological interventions for neuropathic pain.

OBJECTIVE: The present study sought to examine the clinical relevance of the relation between catastrophizing and analgesic response in individuals with neuropathic pain. Clinically meaningful reductions were defined in terms of the magnitude of reductions in pain through the course of treatment, and in terms of the number of patients whose end-of-treatment pain ratings were below $4 / 10$.

METHODS: Patients $(\mathrm{n}=82)$ with neuropathic pain conditions completed a measure of pain catastrophizing at the beginning of a three-week trial examining the efficacy of topical analgesics for neuropathic pain.

RESULTS: Consistent with previous research, high scores on the measure of pain catastrophizing prospectively predicted poorer response to treatment. Fewer catastrophizers than noncatastrophizers showed moderate ( $\geq 2$ points) or substantial reductions in pain ratings through the course of treatment. Fewer catastrophizers than noncatastrophizers achieved end-of-treatment pain ratings below $4 / 10$.

CONCLUSIONS: The results of the present study suggest that the development of brief interventions specifically targeting catastrophic thinking might be useful for enhancing the effects of pharmacological interventions for neuropathic pain. Furthermore, failure to account for the level of catastrophizing might contribute to null findings in clinical trials of analgesic medication.

Key Words: Catastrophizing; Neuropathic pain; Topical analgesics; Treatment efficacy

T has been estimated that there are more than 300,000 patients suffering from neuropathic pain in Canada and more than 3.8 million in the United States $(1,2)$. Neuropathic pain has been defined as "pain arising as a direct consequence of a lesion or disease affecting the somatosensory system" (3). As a result of the aging population and the increase in survival rates following interventions that give rise to neuropathic pain conditions (eg, cancer), the prevalence of neuropathic pain conditions is expected to increase significantly over the next two decades (4).

Pharmacological interventions are the dominant treatment approach for neuropathic pain $(5,6)$. Unfortunately, many clinical trials of available treatments for neuropathic pain have yielded disappointing results, and many patients with neuropathic pain conditions continue to experience ongoing distressing and disabling symptoms of pain $(7,8)$. It has been suggested that as many as one-half of the patients with neuropathic pain conditions are incompletely or totally refractory to available treatments (9).

Recent studies have examined the relationship between pain catastrophizing and pain experience in individuals suffering from neuropathic pain conditions (10). Pain catastrophizing has been defined as

\section{La catastrophisation de la douleur prédit une réponse médiocre aux analgésiques topiques en cas de douleur neuropathique}

HISTORIQUE : Selon des recherches antérieures, de forts taux de catas-
trophisation de la douleur pourraient prédire une moins bonne réponse aux
interventions pharmacologiques pour soulager la douleur neuropathique.
OBJECTIF : La présente étude visait à examiner la pertinence clinique du
lien entre la catastrophisation et la réponse analgésique des personnes
ayant une douleur neuropathique. Des réductions cliniquement significa-
tives étaient définies d'après la magnitude des réductions de la douleur
pendant la durée du traitement et le nombre de patients dont la douleur en
fin de traitement se situait sous les $4 / 10$.

MÉTHODOLOGIE : Les patients $(\mathrm{n}=82)$ ayant des maladies provoquant une douleur neuropathique ont rempli une mesure de catastrophisation de la douleur au début d'un essai de trois semaines portant sur l'efficacité des analgésiques topiques pour soulager la douleur neuropathique.

RÉSULTATS : Conformément aux recherches antérieures, les indices élevés sur la mesure de catastrophisation de la douleur ont prédit prospectivement une moins bonne réponse au traitement. Moins de personnes faisant de la catastrophisation que de personnes n'en faisant pas ont démontré une réduction modérée ( 22 points) ou substantielle d'évaluations de la douleur pendant le traitement. Moins de personnes faisant de la catastrophisation que de personnes n'en faisant pas sont parvenues à une évaluation de la douleur de moins de 4/10 en fin de traitement.

CONCLUSIONS : D'après les résultats de la présente étude, l'élaboration de brèves interventions ciblant expressément la pensée catastrophique pourrait être utile pour améliorer les effets des interventions pharmacologiques pour soulager la douleur neuropathique. De plus, le fait de ne pas tenir compte du niveau de catastrophisation peut contribuer à des observations nulles dans des essais cliniques sur les analgésiques.

${ }^{1}$ Department of Psychology, McGill University, Montreal, Quebec; ${ }^{2}$ Pain Management Unit, Queen Elizabeth II Health Sciences Centre,

Dalhousie University, Halifax, Nova Scotia; ${ }^{3}$ Chronic Pain Centre, Calgary Health Region, Calgary, Alberta; ${ }^{4}$ Department of Pharmacology,

Dalhousie University, Halifax, Nova Scotia

Correspondence: Dr Michael Sullivan, Department of Psychology, McGill University, 1205 Docteur Penfield, Montréal, Québec H3A 1B1.

Telephone 514-398-4455, fax 514-398-4896, e-mail michael.sullivan@mcgill.ca 
catastrophizing-reduction interventions to improve pain outcomes, it is necessary to determine whether the relationship between catastrophizing and treatment response is sufficiently robust to be considered clinically meaningful.

One approach to defining the clinical meaningfulness of pain reduction has been to assess the magnitude of pain reduction achieved by an analgesic agent. It has been suggested that a 2-point reduction on an 11-point numerical rating scale (NRS) represents moderate improvement in pain, and that a 4-point reduction represents a substantial improvement in pain $(18,19)$. Another approach to defining clinical meaningfulness of pain reduction has been to examine the proportion of patients whose pain levels falls below 4 on an 11-point NRS (20). A value of $4 / 10$ corresponds to the boundary between mild and moderate pain.

The primary objective of the present study was to examine the clinical meaningfulness of the relationship between catastrophizing and analgesic response in a sample of patients with neuropathic pain. Patients with varied neuropathic pain conditions completed a measure of catastrophizing before initiating a three-week course of a topical analgesic. Analyses addressed whether high catastrophizers were less likely than low catastrophizers to show a 2-point or greater reduction in pain ratings in response to treatment, and whether fewer catastrophizers than noncatastrophizers achieved post-treatment pain ratings less than $4 / 10$.

\section{METHODS}

\section{Participants}

The study sample comprised 82 patients (41 men, 41 women) who were enrolled in one of two clinical trials examining the efficacy of topical analgesics for neuropathic pain. Patients had diagnoses of diabetic neuropathy $(n=16)$, postherpetic neuralgia $(n=10)$ or postsurgical or post-traumatic neuropathic pain $(n=56)$. The mean age of participants was 51.1 years with a range of 24 to 84 years. The mean $( \pm \mathrm{SD})$ duration of pain was $70.9 \pm 66.8$ months.

\section{Procedure}

The study sample included participants who were recruited from three hospital outpatient pain management units in eastern Canada for enrollment in two clinical trials examining the efficacy of one of three topical analgesics. Part of the study sample $(n=59)$ was drawn from a double-blinded, randomized clinical trial comparing three topical creams containing: $2 \%$ amitriptyline; $1 \%$ ketamine; and combination $2 \%$ amitriptyline/ $1 \%$ ketamine. Of the 140 participants initially assessed for eligibility in this trial, seven refused to participate while 41 did not meet the inclusion criteria. In the data reported in the present study, participants in the placebo group $(n=25)$ were not included. The remaining participants in the study sample $(n=23)$ were drawn from an open-label trial of the combination $2 \%$ amitriptyline/1\% ketamine cream. Eight participants from the double-blinded randomized trial went on to participate in the open-label trial. For the present study, data for these participants were only included in the open-label trial sample $(n=23)$ and not in the double-blinded randomized clinical trial sample $(n=59)$.

In both clinical trials, participants were instructed to clean the area and then apply $4 \mathrm{~mL}$ of cream to the site of maximum pain (size of the area of pain varied) three times a day for three weeks. The vehicle consisted of a moisturizing cream base. All topical formulations were identical in consistency, colour and volume. The results of the randomized clinical trial and open-label trial were reported by Lynch et al $(21,22)$. It is relevant to the present study that no significant group differences in pain reduction were observed across the different treatment conditions.

\section{Measures}

Pain catastrophizing: The Pain Catastrophizing Scale (PCS) was used to measure catastrophic thinking related to pain. The PCS comprises 13 items describing different thoughts and feelings associated with pain. The PCS has been shown to have high internal consistency (coefficient alpha $=0.87$ ) and to be associated with heightened pain, pain behaviour and pain-related disability $(11,15,23)$.

Pain severity: Patients completed a daily pain diary in which they were asked to rate the severity of their pain on an 11-point NRS with the end points of no pain $($ score $=0)$ and severe pain $($ score $=10)$. Pain severity ratings were averaged to yield four pain scores: baseline, week 1 of treatment, week 2 of treatment and week 3 of treatment. For the purposes of the present study, moderate pain reduction was defined as a reduction in pain ratings from baseline to week 3 of $\geq 2$ points, and substantial pain reduction was defined as a reduction in pain ratings of $\geq 4$ points.

\section{Analytic approach}

$t$ tests for independent samples were used to examine sex differences in demographic and dependent measures. Pearson correlations were used to examine relationships among pain severity measures, pain duration, age and the PCS. A median split on the PCS (median = 25) was used to classify patients as catastrophizers and noncatastrophizers. $\chi^{2}$ analyses were used to examine the relationship between level of catastrophizing and the different indexes of treatment response. Logistic regression analyses were used to address the potential influence of initial pain severity. All analyses were conducted using SPSS version 16 (IBM Corporation, USA).

RESULTS
Characteristics of the study sample are presented in Table 1. Women and men did not differ significantly with regard to age ( $\mathrm{t}[80]=1.3$; P not significant $[N S])$, pain duration $(t[80]=0.75 ; P=N S)$, pain severity at baseline $(t[80]=-0.60 ; P=N S)$, change in pain severity $(t[80]=0.65$; $\mathrm{P}=\mathrm{NS}]$ or $\mathrm{PCS}$ scores $(\mathrm{t}[80]=1.4 ; \mathrm{P}=\mathrm{NS})$. Treatment condition assignment $\left(\chi^{2}=1.14 ; \mathrm{P}=\mathrm{NS}\right)$ did not vary significantly as a function of sex. There was a tendency for men to be more likely to have a diagnosis of diabetic neuropathy, but the difference did not attain statistical significance $\left(\chi^{2}=5.1, \mathrm{P}=0.07\right)$.

\section{Correlates of initial pain severity and treatment response}

Correlates of initial pain severity and treatment response are presented in Table 2. Age and pain duration were not significantly correlated with initial pain severity or change in pain. Consistent with previous research, the PCS was positively correlated with initial pain severity (12). The PCS was negatively correlated with pain reduction.

\section{Catastrophizing and treatment response}

Table 3 summarizes the mean pre- and post-treatment pain ratings as a function of level of catastrophizing. Figure 1 shows the number of catastrophizers and noncatastrophizers who showed a 2-point or greater reduction in pain ratings through the course of treatment. Overall, $42 \%$ of patients showed a reduction of $\geq 2$ points in pain ratings. Catastrophizers (30\%) were significantly less likely than noncatastrophizers $(56 \%)$ to show a $\geq 2$-point reduction in pain ratings $\left(\chi^{2}=6.0 ; \mathrm{P}<0.01\right)$.

Overall, $16 \%$ of patients showed a reduction of $\geq 4$ points in pain ratings. Again, catastrophizers (7\%) were less likely than noncatastrophizers $(24 \%)$ to show a $\geq 4$-point reduction in pain ratings $\left(\chi^{2}=4.5\right.$; $\mathrm{P}<0.05$ ) (Figure 1).

Figure 1 shows the number of catastrophizers and noncatastrophizers whose pain ratings fell below 4 at the end of treatment. Overall, $24 \%$ of patients' pain ratings were below $4 / 10$ at the end of treatment. Low scores on catastrophizing were associated with a threefold increase $(36 \%)$ in the probability of achieving end-of-treatment pain ratings below $4 / 10$ compared with high scores on catastrophizing $(12 \%)\left(\chi^{2}=\right.$ 6.2; $\mathrm{P}<0.01)$.

Results from the logistic regression analyses revealed that the relationship between catastrophizing and poor treatment response remained significant even when controlling for initial pain ratings (OR $0.16[95 \%$ CI 0.03 to 0.77$] ; \mathrm{P}<0.05)$. Similarly, the relationship between 
TABLE 1

Sample characteristics $(n=82)$

\begin{tabular}{lccc}
\hline & Women & Men & P \\
\hline $\mathrm{n}$ & 41 & 41 & \\
Age, years & $49.0 \pm 13.4$ & $53.3 \pm 14.7$ & $\mathrm{NS}$ \\
Diagnosis (phn/ptsn/dn), $\mathrm{n}$ & $5 / 32 / 4$ & $5 / 24 / 12$ & $\mathrm{NS}$ \\
Treatment condition (ket/ami/ami-ket), $\mathrm{n}$ & $11 / 10 / 20$ & $7 / 11 / 23$ & $\mathrm{NS}$ \\
Pain duration, months & $65.7 \pm 68.4$ & $76.9 \pm 66.4$ & $\mathrm{NS}$ \\
Baseline pain severity & $7.0 \pm 1.0$ & $6.9 \pm 1.2$ & $\mathrm{NS}$ \\
PCS & $22.8 \pm 11.2$ & $26.2 \pm 10.7$ & $\mathrm{NS}$ \\
\hline
\end{tabular}

Data presented as mean $\pm S D$ unless otherwise indicated. ami Amitriptyline; ami-ket Amitryptyline + ketamine; dn Diabetic neuropathy; ket Ketamine; NS Not significant; PCS Pain Catastrophizing Scale; phn Postherpetic neuralgia; pstn Postsurgical/traumatic neuropathy

TABLE 2

Correlates of initial pain severity and treatment response $(n=82)$

\begin{tabular}{lcc}
\hline & Baseline pain severity & Change in pain \\
\hline Age & 0.05 & 0.04 \\
Pain duration & 0.05 & 0.01 \\
Pain catastrophizing & $0.22^{\star}$ & $0.42^{\star *}$ \\
scale & & \\
\hline
\end{tabular}

${ }^{\star} P<0.05 ;{ }^{*} P<0.01$

\section{TABLE 3}

Mean pain intensity ratings at baseline and at week 3

\begin{tabular}{llll}
\hline & PCS & $\mathbf{n}$ & Mean \pm SD \\
\hline Pain severity at & Noncatastrophizers & 41 & $6.69 \pm 0.99$ \\
baseline (0 to 10) & Catastrophizers & 41 & $7.27 \pm 1.32$ \\
Pain severity week 3 & Noncatastrophizers & 41 & $4.34 \pm 2.09$ \\
(0 to 10) & Catastrophizers & 41 & $6.11 \pm 1.97$ \\
\hline
\end{tabular}

PCS Pain Catastrophizing Scale

catastrophizing and the number of patients with pain scores below 4 at treatment termination remained significant even when controlling for initial pain ratings (OR 0.28 [95\% CI 0.08 to 0.89]; $\mathrm{P}<0.05$ ).

\section{DISCUSSION}

The findings of the present study join growing literature highlighting the importance of psychological factors in the experience of neuropathic pain $(15,24-26)$. The findings are consistent with previous research showing that high levels of catastrophizing predict poorer response to pharmacological interventions for neuropathic pain (12), and extend previous research by showing that the relationship between catastrophizing and poor treatment response can also be considered clinically meaningful.

Overall, $42 \%$ of patients showed moderate improvement in response to treatment and $16 \%$ showed substantial improvement. The magnitude of treatment response is similar to that reported in other studies examining the efficacy of analgesic agents in individuals with neuropathic pain (27-29).

Fewer catastrophizers than noncatastrophizers showed moderate ( $\geq 2$ points) or substantial ( $\geq 4$ points) reductions in pain ratings through the course of treatment. Similarly, fewer catastrophizers than noncatastrophizers achieved end-of-treatment pain ratings below 4/10. Thus, on all indexes of clinically meaningful response, catastrophizing was associated with poorer response to treatment.

The clinical index that most clearly demonstrates the adverse impact of catastrophizing on treatment outcome is the analysis examining the proportion of patients who rated their pain as mild $(<4 / 10)$ at the end of treatment. Catastrophizers' pretreatment pain scores will typically be higher than noncatastrophizers' pretreatment pain scores. Consequently, as a function of regression to the mean, both catastrophizers and noncatastrophizers may experience relative reductions in

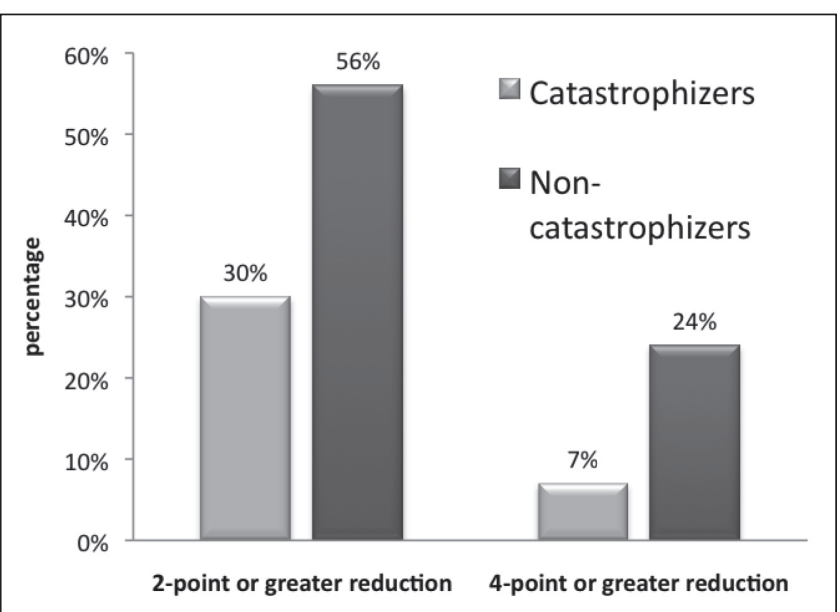

Figure 1) Percentage of catastrophizers and noncatastrophizers with 2-point and 4-point or greater reductions in pain ratings

their pain. However, when assessed in terms of a threshold for treatment success (ie, achieving scores in the mild range of pain), the higher initial pain scores of catastrophizers reduces the likelihood that the treatment success threshold will be attained. As such, catastrophizers are more likely than noncatastrophizers to continue suffering from high levels of persistent pain in spite of the treatment they receive.

The inefficacy of pharmacological interventions for neuropathic pain in individuals with high catastrophizing scores may lead to dose escalation, which could be associated with increasingly adverse consequences for this population. Indeed, studies have demonstrated a significant relationship between high levels of catastrophizing and increased analgesic intake (30). In relation to investigations aimed at determining which medications prove to be most effective in treating neuropathic pain, catastrophizers' initial pretreatment pain scores may also serve to obscure the true effects of trial medications, thus leading to inaccurate conclusions regarding their efficacy.

The mechanisms by which catastrophizing interferes with the response to analgesics remain unclear. However, accumulating evidence suggests that catastrophic thinking may be associated with dysregulation of endogenous opioid pain-control systems (31). In a study investigating postsurgical pain following breast cancer surgery, Jacobsen et al (30) found that individuals with high levels of catastrophizing required higher doses of postoperative opioid analgesics to control their postsurgical pain. A more recent study by Goodin et al (31) found that pain catastrophizing was negatively associated with diffuse noxious inhibitory controls, a psychophysical measure of endogenous pain inhibition, suggesting that high levels of pain catastrophizing may be related to a disruption in the endogenous modulation of pain.

Several psychological and rehabilitative interventions have been shown to yield reductions in catastrophic thinking (32-34). The results of the present research suggest that interventions specifically designed to reduce catastrophizing might similarly yield a better treatment response for patients with neuropathic pain conditions.

It is possible that emotional disclosure techniques might be useful in reducing pain patients' tendency to focus excessively on pain symptoms. Previous research has shown that emotional disclosure manipulations can lead to decreases in emotional distress and reduced preoccupation with emotionally laden information (35). Similarly, the absence of emotional disclosure has been linked to increased thought intrusions and a variety of negative health outcomes (36). Sullivan and Neish (37) showed that high catastrophizers who were provided with an opportunity to disclose their emotional concerns before undergoing dental treatment, reported less pain than high catastrophizers who did not disclose. Emotional disclosure techniques can be effectively incorporated into clinical interviews, and have been shown to have beneficial impact even after one session $(37,38)$. 
Fear reduction techniques might also be an important component of interventions designed to target catastrophizing because mechanisms related to fear might contribute to alarmist reactions to pain stimuli $(39,40)$. Because pain catastrophizing and pain-related fear are partially overlapping constructs, the fear component of catastrophizing might lead individuals to process information about pain-related stimuli preferentially $(41,42)$. Exposure interventions have been shown to be effective in yielding reductions in fear and catastrophic thinking (43). Cognitive techniques designed to reduce the threat value of pain symptoms might also be useful in reducing the pain focus of high catastrophizers (44).

Finally, it is possible that activity-mobilization interventions might provide a useful alternative to cognitive distraction strategies for assisting high catastrophizers in reducing their attentional focus on pain (33). Because activity involvement demands attention, focus on activity might limit the cognitive resources that can be used to attend to pain-related stimuli. Although clinical trials evaluating the most effective approaches to reducing catastrophic thinking have yet to be conducted, there are indications that activity-based interventions can yield significant reductions in catastrophic thinking $(45,46)$.

The bulk of studies demonstrating the efficacy of catastrophizingreduction techniques involved treatment programs that typically extended over a period of 10 to 12 weeks and used functional improvement as the main objective of treatment. Considered either in terms of duration or treatment focus, these interventions might not be entirely applicable in the context of improving response to analgesic medication. The development and evaluation of new approaches to reducing catastrophic thinking in individuals with neuropathic pain may be a fruitful line of inquiry.

Caution must be exercised in the interpretation of the present findings. First, the data were drawn from patients who participated in clinical trials for the treatment of neuropathic pain. Volunteers for clinical trials likely differ in important ways from patients who typically seek treatment for neuropathic pain. In addition, factors associated with treatment response to topical analgesics might also differ in important ways from factors associated with treatment response to other modes of administration. Similarly, the mechanisms of action of topical agents might differ from mechanisms of action of other routes of medication administration. Finally, it is difficult to address whether the exclusion of high catastrophizers from the data would lead to a significant effect of the drug treatment within the current study sample. Some of the cases were drawn from an open-label trial in which there was no comparison group. However, in the secondary data analysis of a subset to the data presented in the present article, the removal of high catastrophizing scores led to a significant effective treatment for individuals who received a combination of amitriptyline and ketamine. These analyses are reported in a separate publication (26).

In spite of these limitations, the findings of the present study join growing literature showing that catastrophizing interferes with the effectiveness of analgesics. This is likely to have significant implications for the detection of treatment effects for the relief of pain. The present study supports the importance of including psychological measures in clinical trials, not only as important outcome measures, but also as determinants of treatment response (47). In the present study, the adverse influence of catastrophizing on treatment response was demonstrated using three different indexes of clinical significance. The effect sizes observed may be sufficient to obscure actual treatment effects, resulting in null findings in trials that do not control for the level of catastrophizing. Future research will need to examine the techniques that are most effective in reducing the pain focus of high catastrophizers. Future research will also need to examine whether interventions designed to specifically target catastrophic thinking influence treatment response to analgesic medication of neuropathic pain.

ACKNOWLEDGEMENTS: The authors thank Paulette Nauss for her assistance in data collection. The authors also thank Nathalie Gauthier and Isabelle Tremblay who completed data entry for this project. The work reported in this article is drawn from two clinical trials funded by EpiCept Corporation. This work was partially supported by a grant from the Canadian Institutes for Health Research.

\section{REFERENCES}

1. Bouhassira D, Lanteri-Minet M, Attal N, Laurent B, Touboul C Prevalence of chronic pain with neuropathic characteristics in the general population. Pain 2008;136:380-7.

2. Tarride JE, Collet JP, Choiniere M, Rousseau C, Gordon A. The economic burden of neuropathic pain in Canada. J Med Econ 2006;9:55-68.

3. Treede RD JT, Campbell JN, Cruccu G, et al. Neuropathic pain: Redefinition and a grading system for clinical and research purposes. Neurology 2008;70:130-5.

4. Dworkin RH. An overview of neuropathic pain: Syndromes, symptoms, signs, and several mechanisms. Clin J Pain 2002;18:343-9.

5. Eisenberg E, McNicol ED, Carr DB. Efficacy and safety of opioid agonists in the treatment of neuropathic pain of nonmalignant origin: Systematic review and meta-analysis of randomized controlled trials. JAMA 2005;293:3043-52.

6. Dieleman JP, Kerklaan J, Huygen FJ, Bouma PA, Sturkenboom MC. Incidence rates and treatment of neuropathic pain conditions in the general population. Pain 2008;137:681-8.

7. Vadalouca A, Siafaka I, Argyra E, Vrachnou E, Moka E. Therapeutic management of chronic neuropathic pain: An examination of pharmacologic treatment. Ann NY Acad Sci 2006;1088:164-86.

8. Cherny NI. The treatment of neuropathic pain: From hubris to humility. Pain 2007;132:225-6.

9. McDermott AM, Toelle TR, Rowbotham DJ, Schaefer CP, Dukes EM. The burden of neuropathic pain: Results from a cross-sectional survey. Eur J Pain 2006;10:127-35.

10. Turner JA, Jensen MP, Warms CA, Cardenas DD. Catastrophizing is associated with pain intensity, psychological distress, and pain-related disability among individuals with chronic pain after spinal cord injury. Pain 2002;98:127-34.
11. Sullivan M, Bishop S, Pivik J. The Pain Catastrophizing Scale: Development and validation. Psychological Assessment 1995;7:524-32.

12. Sullivan MJL, Thorn B, Haythornthwaite JA, et al. Theoretical perspectives on the relation between catastrophizing and pain. Clin J Pain 2001;17:52-64.

13. Haythornthwaite J, Clark M, Pappagallo M, Raja S. Pain coping strategies play a role in the persistence of pain in post-herpetic neuralgia. Pain 2003;106:453-60.

14. Jensen MP, Ehde DM, Hoffman AJ, Patterson DR, Czerniecki JM, Robinson LR. Cognitions, coping and social environment predict adjustment to phantom limb pain. Pain 2002;95:133-42.

15. Sullivan MJ, Lynch ME, Clark AJ. Dimensions of catastrophic thinking associated with pain experience and disability in patients with neuropathic pain conditions. Pain 2005;113:310-5.

16. Fillingim RB, Hastie BA, Ness TJ, Glover TL, Campbell CM, Staud R. Sex-related psychological predictors of baseline pain perception and analgesic responses to pentazocine. Biol Psychol 2005;69:97-112.

17. Edwards RR, Bingham CO, Bathon J, Haythornthwaite JA. Catastrophizing and pain in arthritis, fibromyalgia, and other rheumatic diseases. Arthritis Rheum 2006;55:325-32.

18. Dworkin RH, Turk DC, McDermott MP, et al. Interpreting the clinical importance of group differences in chronic pain clinical trials: IMMPACT recommendations. Pain 2009;146:238-44.

19. Farrar JT, Young JP, LaMoreaux L, Werth JL, Poole RM. Clinical importance of changes in pain intensity measured on an 11-point numerical pain rating scale. Pain 2001;94:149-58.

20. Farrar JT, Portenoy RK, Berlin JA, Kinman JL, Strom BL. Defining clinically important difference in pain outcome measures. Pain 2000;88:287-94.

21. Lynch ME, Clark AJ, Sawynok J, Sullivan MJ. Topical 2\% amitriptyline and $1 \%$ ketamine in neuropathic pain syndromes: 
A randomized, double-blind, placebo-controlled trial. Anesthesiology 2005;103:140-6.

22. Lynch ME, Clark AJ, Sawynok J, Sullivan MJ. Topical amitriptyline and ketamine in neuropathic pain syndromes: An open-label study. J Pain 2005;6:644-9.

23. Sullivan MJL, Martel MO, Tripp D, Savard A, Crombez G. The relation between catastrophizing and the communication of pain experience. Pain 2006;122:282-8.

24. Haythornthwaite JA, Benrud-Larson LM. Psychological aspects of neuropathic pain. Clin J Pain 2000;16(2 Suppl):S101-5.

25. Daniel HC, Narewska J, Serpell M, Hoggart B, Johnson R, Rice AS. Comparison of psychological and physical function in neuropathic pain and nociceptive pain: Implications for cognitive behavioral pain management programs. Eur J Pain 2008;12:731-41.

26. Sullivan MJL, Lynch ME, Clark AJ, Mankovsky T, Sawynok J. Catastrophizing and treatment outcome: Impact on response to placebo and active treatment outcome. Contemporary Hypnosis 2008;29:129-40.

27. Baron R, Freynhagen R, Tolle TR, et al. The efficacy and safety of pregabalin in the treatment of neuropathic pain associated with chronic lumbosacral radiculopathy. Pain 2010;150:420-7.

28. Finnerup NB, Sindrup SH, Jensen TS. The evidence for pharmacological treatment of neuropathic pain. Pain 2010;150:573-81.

29. Campbell CM, Edwards RR. Mind-body interactions in pain: The neurophysiology of anxious and catastrophic pain-related thoughts. Transl Res 2009;153:97-101.

30. Jacobsen PB, Butler RW. Relation of cognitive coping and catastrophizing to acute pain and analgesic use following breast cancer surgery. J Behav Med 1996;19:17-29.

31. Goodin BR, McGuire L, Allshouse M, et al. Associations between catastrophizing and endogenous pain-inhibitory processes: Sex differences. J Pain 2009;10:180-90.

32. Adams H, Ellis T, Stanish WD, Sullivan MJ. Psychosocial factors related to return to work following rehabilitation of whiplash injuries. J Occup Rehabil 2007;17:305-15.

33. Sullivan MJL, Adams H, Rhodenizer T, Stanish WD. A psychosocial risk factor- targeted intervention for the prevention of chronic pain and disability following whiplash injury. Phys Ther 2006;86:8-18.

34. Smeets RJ, Vlaeyen JW, Kester AD, Knottnerus JA. Reduction of pain catastrophizing mediates the outcome of both physical and cognitive-behavioral treatment in chronic low back pain. J Pain 2006;7:261-71.
35. Stiles W. Disclosure as a speech act: Is it psychotherapeutic to disclose? In: Pennebaker J, ed. Emotion, Disclosure and Health. Washinton, DC: American Psychological Association, 1995.

36. Koster EH, Rassin E, Crombez G, Naring GW. The paradoxical effects of suppressing anxious thoughts during imminent threat. Behav Res Ther 2003;41:1113-20.

37. Sullivan MJ, Neish N. The effects of disclosure on pain during dental hygiene treatment: The moderating role of catastrophizing. Pain 1999;79:155-63.

38. Cepeda MS, Chapman CR, Miranda N, et al. Emotional disclosure through patient narrative may improve pain and well-being: Results of a randomized controlled trial in patients with cancer pain. J Pain Symptom Manage 2008;35:623-31.

39. Keogh E, Dillon C, Georgiou G, Hunt C. Selective attentional biases for physical threat in physical anxiety sensitivity. J Anxiety Disord 2001;15:299-315.

40. Vlaeyen JW, Linton SJ. Fear-avoidance and its consequences in chronic musculoskeletal pain: A state of the art. Pain 2000;85:317-32.

41. Vangronsveld K, Van Damme S, Peters M, Vlaeyen J, Goossens M, Crombez G. An experimental investigation on attentional interference by threatening fixations of the neck in patients with chronic whiplash syndrome. Pain 2007;127:121-8.

42. Van Damme S, Crombez G, Eccleston C, Goubert L. Impaired disengagement from threatening cues of impending pain in a crossmodal cueing paradigm. Eur J Pain 2004;8:227-36.

43. Vlaeyen JW, De Jong JR, Onghena P, Kerckhoffs-Hanssen M, Kole-Snijders AM. Can pain-related fear be reduced?

The application of cognitive-behavioural exposure in vivo. Pain Res Manag 2002; 7:144-53.

44. Gatchel R, Peng YB, Peters ML, Fuchs PN, Turk DC. The biopsychosocial approach to chronic pain: Scientific advances and future directions. Psychol Bull 2007;133:581-624.

45. Adams H, Ellis T, Stanish WD, Sullivan MJ. Psychosocial factors related to return to work following rehabilitation of whiplash injuries. J Occup Rehabil 2007;17:305-15.

46. Sullivan MJL, Adams H. Psychosocial techniques to augment the impact of physical therapy interventions for low back pain. Physiother Canada. 2010;62:180-9.

47. Turk DC, Dworkin RH, Allen RR, et al. Core outcome domains for chronic pain clinical trials: IMMPACT recommendations. Pain 2003;106:337-45. 


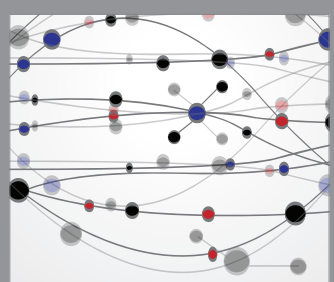

The Scientific World Journal
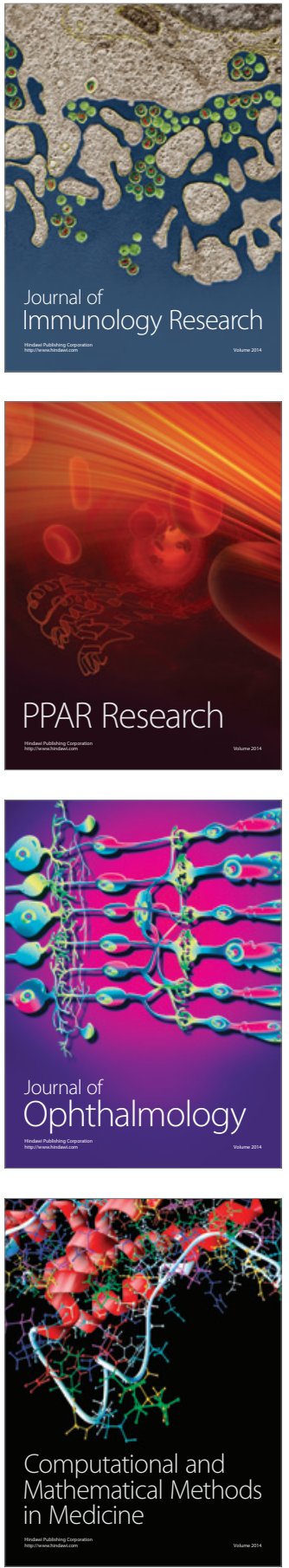

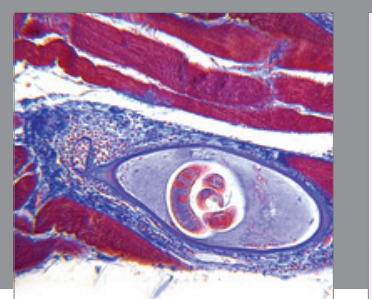

Gastroenterology Research and Practice

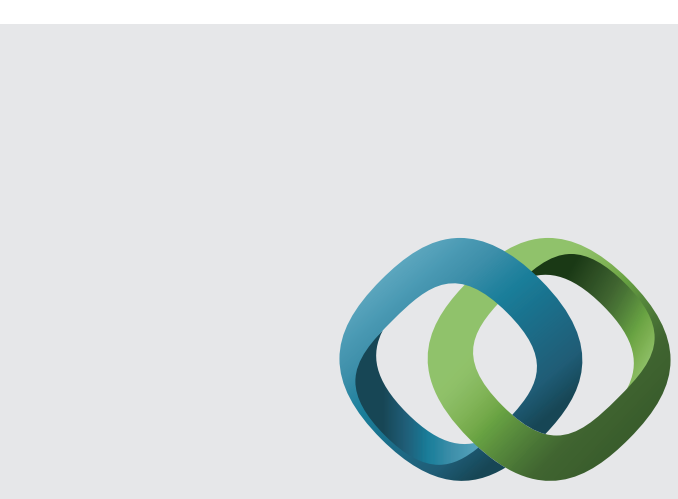

\section{Hindawi}

Submit your manuscripts at

http://www.hindawi.com
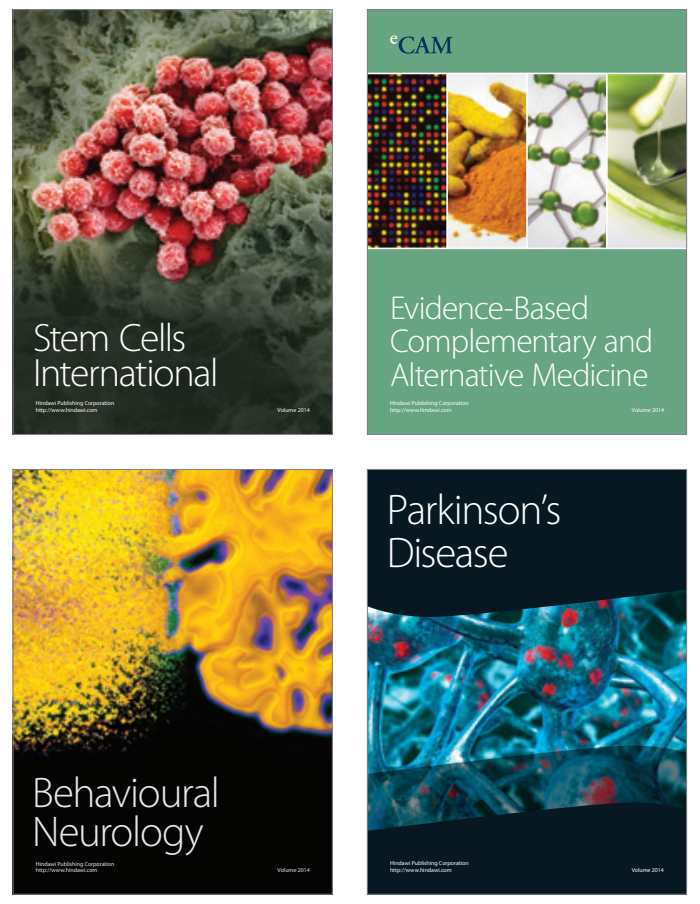
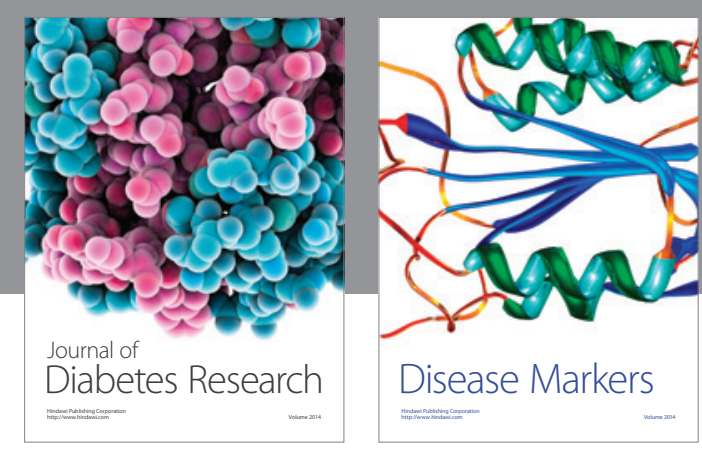

Disease Markers
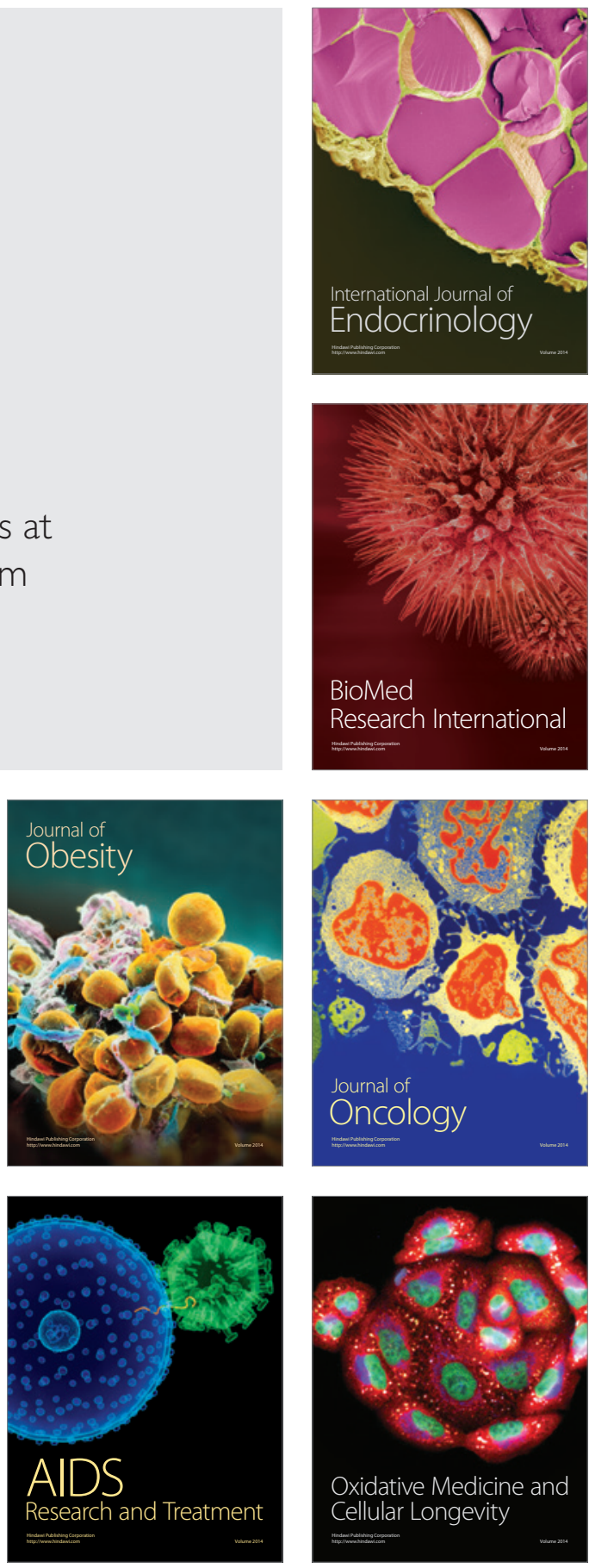